\title{
ART influences HIV persistence in the female reproductive tract and cervicovaginal secretions
}

\author{
Rikke Olesen, ${ }^{1,2}$ Michael D. Swanson, ${ }^{1}$ Martina Kovarova, ${ }^{1}$ Tomonori Nochi, ${ }^{1}$ Morgan Chateau, ${ }^{1}$ Jenna B. Honeycutt, ${ }^{1}$ Julie M. Long, ${ }^{1}$ \\ Paul W. Denton, ${ }^{1}$ Michael G. Hudgens, ${ }^{3}$ Amy Richardson, ${ }^{3}$ Martin Tolstrup, ${ }^{2}$ Lars Østergaard, ${ }^{2}$ Angela Wahl, ${ }^{1}$ and J. Victor Garcia ${ }^{1}$ \\ 'Division of Infectious Diseases, Center for AIDS Research, University of North Carolina (UNC), School of Medicine, Chapel Hill, North Carolina, USA. ²Department of Infectious Diseases, Aarhus University \\ Hospital, Aarhus, Denmark. 르epartment of Biostatistics, UNC, Chapel Hill, North Carolina, USA.
}

\begin{abstract}
The recently completed HIV prevention trials network study 052 is a landmark collaboration demonstrating that HIV transmission in discordant couples can be dramatically reduced by treating the infected individual with antiretroviral therapy (ART). However, the cellular and virological events that occur in the female reproductive tract (FRT) during ART that result in such a drastic decrease in transmission were not studied and remain unknown. Here, we implemented an in vivo model of ART in BM/liver/thymus (BLT) humanized mice in order to better understand the ability of ART to prevent secondary HIV transmission. We demonstrated that the entire FRT of BLT mice is reconstituted with human CD4+ cells that are shed into cervicovaginal secretions (CVS). A high percentage of the CD4 ${ }^{+} \mathrm{T}$ cells in the FRT and CVS expressed CCR5 and therefore are potential HIV target cells. Infection with HIV increased the numbers of CD4+ and CD8+ $T$ cells in CVS of BLT mice. Furthermore, HIV was present in CVS during infection. Finally, we evaluated the effect of ART on HIV levels in the FRT and CVS and demonstrated that ART can efficiently suppress cell-free HIV-RNA in CVS, despite residual levels of HIV-RNA+ cells in both the FRT and CVS.
\end{abstract}

\section{Introduction}

Most clinical trials of HIV prevention have aimed at preventing HIV acquisition by topical or systemic administration of preventative antiretroviral drugs to uninfected individuals (1-10). Results from these clinical trials have shown either partial or no protection. The basis for these discordant results are not yet clear and have been postulated to be due to a combination of a lack of adherence and inadequate drug levels at the site of exposure $(5,7,11)$. In contrast, the HIV prevention trials network study 052 (HPTN 052) demonstrated $93 \%$ protection against secondary heterosexual transmission when infected individuals received early antiretroviral therapy (ART) (12). Importantly, no linked partner infections were observed when the HIV-infected participant was stably suppressed by ART. The prevailing hypothesis for the success of HPTN 052 is that ART reduces genital cell-free and/or genital cell-associated HIV to levels that are too low to support HIV transmission (12). This hypothesis is supported by observational studies suggesting a strong correlation between plasma/genital HIV-RNA levels and risk of heterosexual transmission $(13,14)$; it is also supported by the ability of ART to decrease the genital levels of HIV in both men and women (15-17). There is very limited data in the literature to determine whether transmission occurs from cell-free virus only or if produc-

Note regarding evaluation of this manuscript: Manuscripts authored by scientists associated with Duke University, The University of North Carolina at Chapel Hill, Duke-NUS, and the Sanford-Burnham Medical Research Institute are handled not by members of the editorial board but rather by the science editors, who consult with selected external editors and reviewers.

Conflict of interest: The authors have declared that no conflict of interest exists. Submitted: April 13, 2012; Accepted: December 10, 2015.

Reference information: / Clin Invest. 2016;126(3):892-904. doi:10.1172/JCI64212. tively infected cells themselves can transmit HIV in the absence of cell-free virions (18).

In order to better understand the ability of ART to prevent secondary transmission of HIV, we used a small animal model of HIV infection to further characterize key virological and immunological events that occur in the female reproductive tract (FRT) during ART. We designed the following experiments using $\underline{B}$ M/liver/thymus humanized mice (BLT mice). First, we performed a detailed and comprehensive phenotypic characterization of the human lymphocyte subsets present in the FRT and cervicovaginal secretions (CVS). Next, we analyzed HIV levels and cellular dynamics in CVS during HIV infection. Finally, we evaluated virological suppression and cellular dynamics in the FRT and CVS during ART. We provide data demonstrating that HIV replication occurs in CVS soon after exposure and continues during the course of infection. This is followed by an increase of $\mathrm{CD} 4^{+} \mathrm{T}$ cells in CVS, providing additional target cells for infection. This $\mathrm{CD} 4^{+} \mathrm{T}$ cell increase is followed by a delayed increase of $\mathrm{CD}^{+} \mathrm{T}$ cells in CVS. Surprisingly, despite the strong suppressive effect of ART on the viral load in CVS, HIV$\mathrm{RNA}^{+}$cells were still present in both the FRT and CVS. However, when analyzed ex vivo, cells isolated from the FRT and CVS of ART-suppressed BLT mice did not transmit HIV in a coculture assay. Thus, our results provide in vivo evidence supporting the hypothesis behind the success of HPTN 052 (12) for limiting sexual transmission from HIV-infected women.

\section{Results}

Reconstitution of the FRT of BLT mice with human $C D 4^{+}$cells. BLT mice were prepared as previously described (19-23) and were well reconstituted with human hematopoietic cells $\left(\mathrm{CD} 45^{+}\right)$in peripheral blood $(\mathrm{PB})$ (median $70 \%$, range $22-95$, interquartile 
range $56-78, n=142$ ). In addition, we used IHC to assess reconstitution and distribution of HIV target cells (human $\mathrm{CD} 4^{+}$cells, $\mathrm{CD}^{+} 8^{+}$myeloid/immature DC, and CD11c ${ }^{+}$DCs) in the FRT of BLT mice (Figure 1 and Supplemental Figures 1 and 2; supplemental material available online with this article; doi:10.1172/ JCI64212DS1). Human CD4 ${ }^{+}$cells were observed throughout the FRT. Specifically, in the vagina, human $\mathrm{CD} 4^{+}$cells were mainly observed in the lamina propria, while few $\mathrm{CD} 4^{+}$cells were present in the epithelium. Vaginal $\mathrm{CD} 4^{+}$cells were dispersed throughout the lamina propria both as single cells and as focal aggregates in close proximity to the epithelial layer, similar to their distribution in healthy women $(24,25)$. Cervical CD $4^{+}$cells were present as single cells close to the epithelium and distributed throughout the lamina propria. In the uterine endometrium, $\mathrm{CD} 4^{+}$cells were found in the stroma both as small clusters closely adjacent to the epithelial layer and scattered as single cells, resembling their distribution in women (24-26). Similarly, inspection of the FRT for the presence of human macrophages and DCs demonstrated that, like in humans, these cell types are dispersed throughout the lamina propria of the vagina, cervix, and uterus (refs. 24, 26-28, and Supplemental Figures 1 and 2). Furthermore, like in women, macrophages and DCs in BLT mice were more abundant in the cervical mucosa than the vaginal mucosa (24). Together, these results show the efficient repopulation and adequate distribution of the human target cells postulated to be involved in vaginal HIV transmission throughout the entire FRT of BLT mice (29).

The majority of human $T$ cells in the FRT and CVS of BLT mice express a memory phenotype and the CCR5 HIV coreceptor. After establishing the presence and distribution of human $\mathrm{CD} 4^{+}$cells in the FRT of BLT mice (Figure 1), we proceeded to compare their cell surface phenotype to those from PB and CVS (Figure 2). CVS samples from BLT mice were collected, and cells were isolated for analysis. Cells were also isolated from the entire FRT. CVS and FRT samples were then analyzed for the presence of human $\mathrm{CD}^{+}$and $\mathrm{CD}^{+} \mathrm{T}$ cells and compared with samples obtained from $\mathrm{PB}$ (Figure 2, A and B). Our results show that, in all 3 compartments, the majority of human $\left(C D 45^{+}\right)$hematopoietic cells were $\mathrm{CD}^{+} \mathrm{T}$ cells (Figure 2, A and B) and that the level of CD4 ${ }^{+}$ $\mathrm{T}$ cells in all 3 compartments was the same prior to infection with HIV (Figure $2 \mathrm{~B}$ ) (PB vs. FRT, $P=0.22$; PB vs. CVS, $P=0.22$; and CVS vs. FRT, $P=0.22$ ). In addition, when compared with $P B$ $\mathrm{T}$ cells, a significantly higher percentage of cells in the FRT and CVS expressed CCR5, the primary HIV coreceptor involved in mucosal HIV transmission (ref. 30 and Figure $2 \mathrm{C})\left(\mathrm{CD} 4^{+} \mathrm{T}\right.$ cells: FRT vs. $\mathrm{PB}, P=0.01$, and CVS vs. $\mathrm{PB}, P<0.0001$; $\mathrm{CD}^{+} \mathrm{T}$ cells: FRT vs. $\mathrm{PB}, P=0.01$, and CVS vs. $\mathrm{PB}, P<0.0001)$. This is consistent with what has been observed in women and with the preferential mucosal transmission of CCR5-tropic $\operatorname{HIV}(31,32)$.

To confirm that cells in the FRT of BLT mice have a similar memory phenotype as in women $(24,33,34)$, we characterized the naive-memory phenotype of $\mathrm{T}$ cell subsets in $\mathrm{PB}$, the FRT, and CVS (naive: $\mathrm{CD}^{2} 5 \mathrm{RA}^{+} \mathrm{CD} 27^{+}$; central memory $(\mathrm{CM})$ : $\mathrm{CD} 45 \mathrm{RA}^{-} \mathrm{CD} 27^{+}$; effector memory (EM): CD45RA-CD27-)(Figure 2, D and E). The majority of $\mathrm{CD}^{+}$and $\mathrm{CD} 8^{+}$human $\mathrm{T}$ cells in $\mathrm{PB}$ of BLT mice had a naive phenotype $\left(\mathrm{CD} 45 \mathrm{RA}^{+} \mathrm{CD} 27^{+}\right)\left(\mathrm{CD} 4^{+} \mathrm{T}\right.$ cells: naive vs. $\mathrm{CM}$, $P<0.0001$, and naive vs. EM, $P<0.0001 ; \mathrm{CD}^{+} \mathrm{T}$ cells: naive vs. $\mathrm{CM}, P<0.0001$, and naive vs. EM, $P<0.0001)$. In contrast, the majority of human $\mathrm{T}$ cells in CVS had a CM phenotype $\left(\mathrm{CD}^{+}\right.$and $\mathrm{CD}^{+}$T cells: $\mathrm{CM}$ vs. naive, $P<0.0001$, and CM vs. $\left.\mathrm{EM}, P<0.0001\right)$. Also notable were significantly higher levels of $\mathrm{CD}^{+} \mathrm{EM} \mathrm{T}$ cells (CD45RA-CD27-) in CVS and the FRT compared with PB (Figure 2D) (EM cells in FRT vs. PB, $P=0.022$ and CVS vs. $P B, P<0.0001$ ) and of $\mathrm{CD}^{+}$EM T cells in CVS compared with $\mathrm{PB}(P<0.0001)$ (Figure $2 \mathrm{E})$. Increasing evidence suggests that $\mathrm{CD} 4^{+} \mathrm{T}$ cells expressing the integrin $\alpha 4 \beta 7$ heterodimer (a mucosal homing receptor) are especially susceptible to HIV infection and may play a central role in the earliest steps of transmission $(35,36)$. Therefore, we investigated the expression of $\alpha 4 \beta 7$ on memory CD $4^{+} \mathrm{T}$ cells in $\mathrm{PB}$ of humans and $\mathrm{PB}$, FRT, and CVS of BLT mice. The percentage of memory CD $4^{+} \mathrm{T}$ cells in PB expressing $\alpha 4 \beta 7$ was similar in humans and BLT mice (Supplemental Figure 3). Furthermore, memory $\mathrm{CD} 4^{+} \mathrm{T}$ cell expression of $\alpha 4 \beta 7$ in the FRT and CVS of BLT mice was significantly lower than in $\mathrm{PB}$ (PB vs. FRT, $P=0.003$, and PB vs. CVS, $P<0.0001$ ) (Supplemental Figure 3), which is similar to what is observed in women, where fewer FRT memory CD $4^{+} \mathrm{T}$ cells express $\alpha 4 \beta 7$ when compared with $\mathrm{PB}$ (32). We also observed no difference in $\mathrm{CD} 4^{+}$memory $\mathrm{T}$ cell $\alpha 4 \beta 7$ expression between the FRT and CVS of BLT mice $(P=0.13)$ (Supplemental Figure 3). In summary, the majority of lymphocytes in the FRT and CVS of BLT mice were memory T cells expressing CCR5, which is remarkably similar to what is observed in the FRT of humans $(32,33,37)$.

$H I V$ and HIV-infected cells are present in the FRT and CVS of $B L T$ mice. We established that HIV-infected cells are present in the FRT of HIV-infected BLT mice by analyzing different regions of the FRT from a BLT mouse infected vaginally with HIV-1 ${ }_{\mathrm{JR}-\mathrm{CSF}}$, a well-characterized T cell tropic isolate that utilizes CCR5 as a coreceptor for entry (ref. 38 and Figure 3A). HIV-RNA was also readily detected in CVS from infected mice (Figure 3, $\mathrm{B}-\mathrm{D})$. As seen in humans, there was an overall significant positive linear correlation between the viral load in plasma and CVS (Spearman's correlation coefficient $=0.55$ [95\% CI, 0.36-0.69, $P<0.001, n=51]$ ) (Figure $3 \mathrm{E}$ and refs. 31, 39-42).

$H I V$ infection results in a dramatic reduction in the percentage of $\mathrm{CD}^{+} \mathrm{T}$ cells in the FRT and CVS. Following HIV infection, mucosal tissues like the gut undergo a rapid depletion of $\mathrm{CD}^{+} \mathrm{T}$ cells (43), and this hallmark of HIV infection is faithfully recapitulated in BLT mice $(20,21)$. A significant decrease in the percentage of cervical $\mathrm{CD}^{+} \mathrm{T}$ cells during chronic HIV infection in women has also been observed $(31-33,37,44)$. In order to investigate these phenomena in the FRT and CVS of BLT mice, we analyzed CD $4^{+} \mathrm{T}$ cell levels longitudinally after HIV vaginal exposure. Prior to HIV infection, the levels of $\mathrm{CD}^{+}$ T cells were similar in the FRT, CVS, and PB (Figure 2B and Figure $4, \mathrm{~A}-\mathrm{D})$. After vaginal infection, there was a decline in the levels of human $\mathrm{CD}^{+} \mathrm{T}$ cells in all 3 compartments (Figure 4, A and D). Specifically, a modest decline to approximately $70 \%$ was observed in the $\mathrm{PB}$, whereas $\mathrm{CD} 4^{+} \mathrm{T}$ cell levels in CVS incurred a significantly more dramatic decrease to approximately $5 \%$ (for weeks 3-7, $P=0.0001-0.0042)$. Interestingly, the levels of CD $4^{+}$ $\mathrm{T}$ cells in the FRT also declined but stabilized at about 30\%, an intermediate level between PB and CVS (Figure 4, A and D).

HIV infection after mucosal exposure occurs by 3 main routes: rectal, vaginal, and oral. BLT mice are an outstanding model for each of these individual modes of transmission (20-23, 45-48). In 

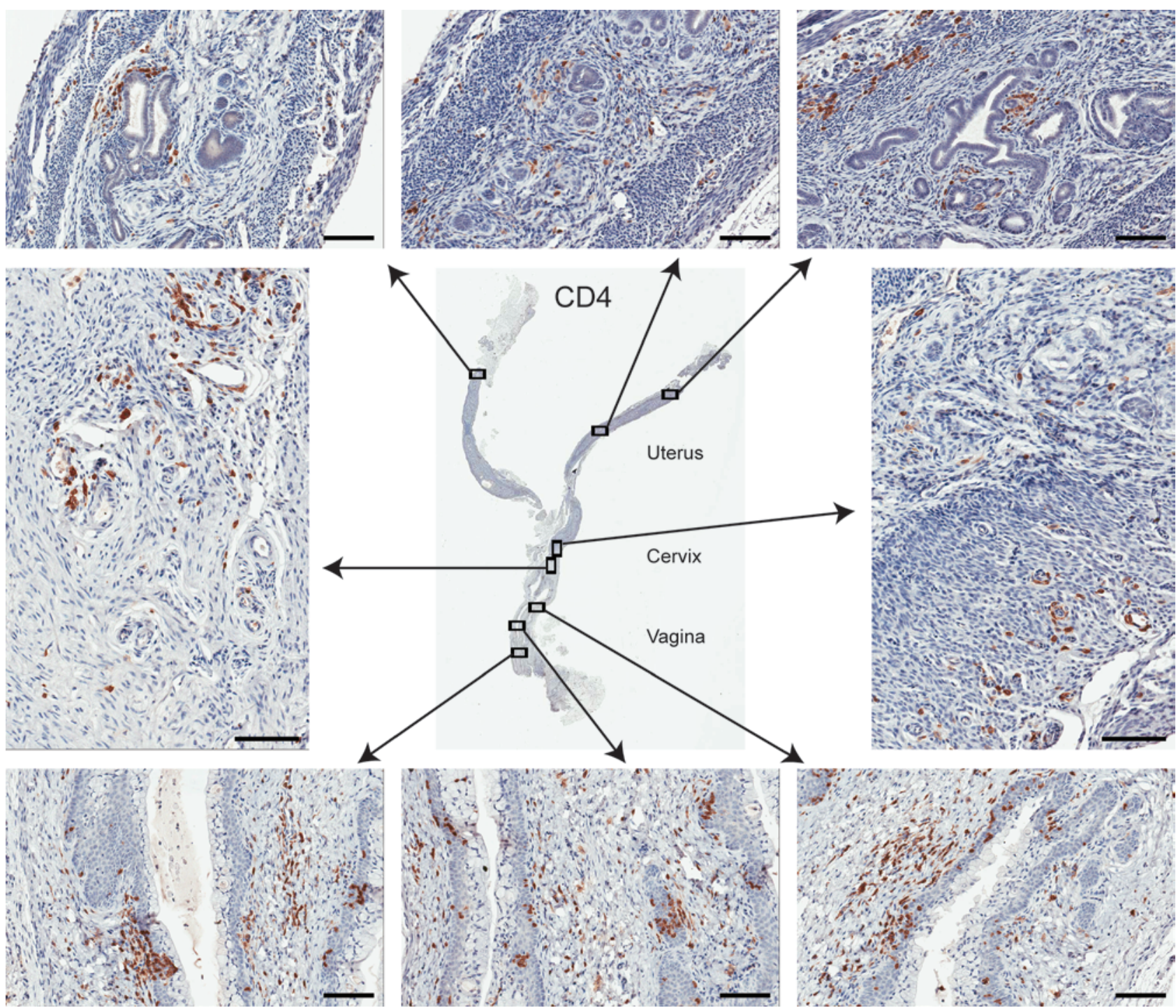

CD4
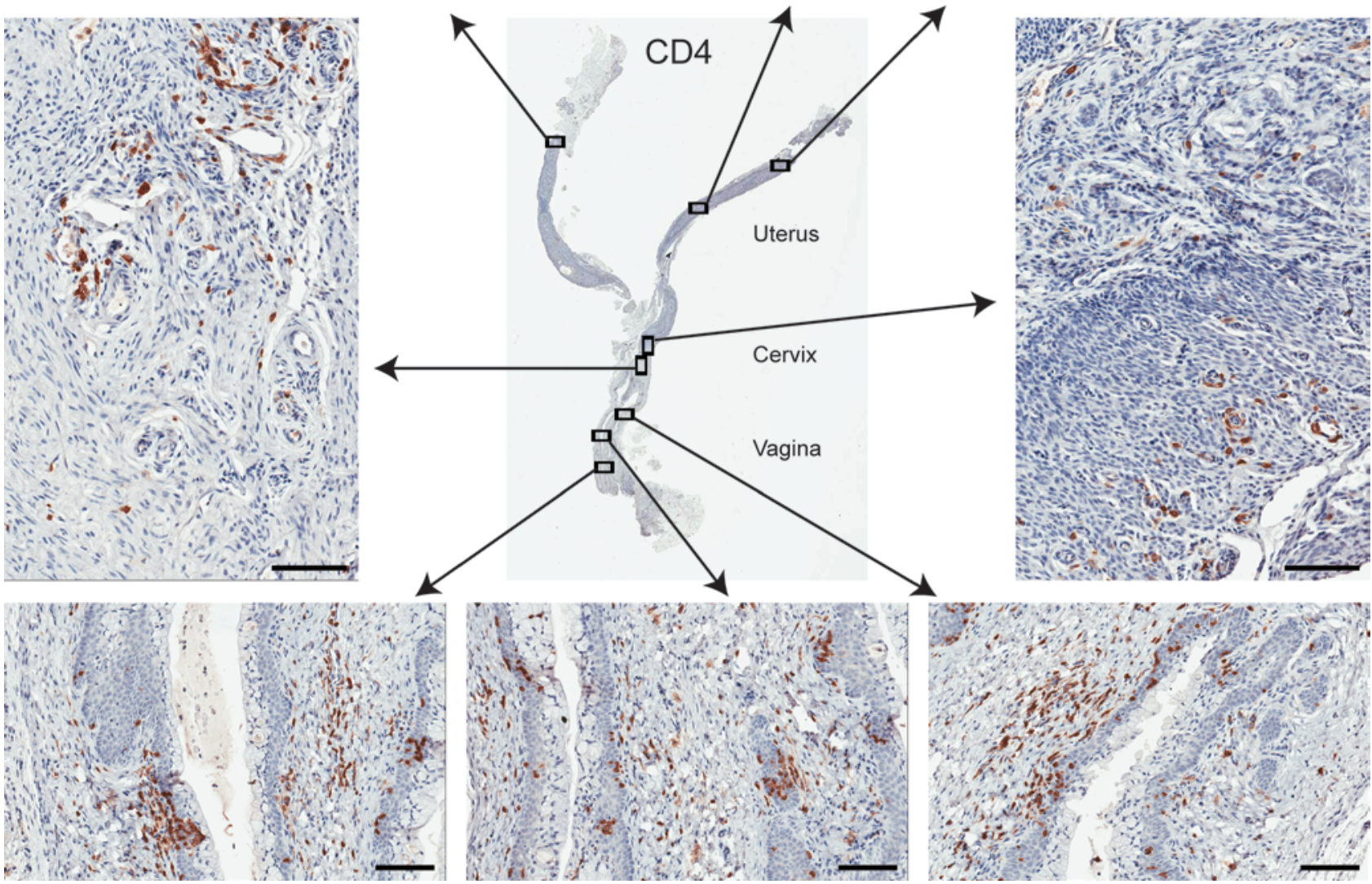

Figure 1. Human CD4 ${ }^{+}$T cells are present throughout the FRT of BLT mice. Immunohistochemical analysis of the entire FRT of a HIV- BLT mouse demonstrates the presence of $\mathrm{CD4} 4^{+}$cells in the vagina, cervix, and uterus. CD4+ cells are stained brown. Scale bars: $100 \mu \mathrm{m}$.

order to understand the cellular dynamics that occur in the FRT after local versus distal HIV infection, we evaluated all 3 modes of mucosal HIV acquisition following exposure to cell-free and/or cell-associated HIV (Supplemental Table 1). Specifically, to complement the data presented above obtained after vaginal exposure, we analyzed the levels of human $\mathrm{CD} 4^{+} \mathrm{T}$ cells in PB, FRT, and CVS following rectal and oral HIV exposures (Figure 4, B-D). Longitudinal analysis demonstrated a decrease in the percentage of $\mathrm{CD} 4^{+} \mathrm{T}$ cells in the FRT and CVS following rectal and oral infection (Figure $4, \mathrm{~B}-\mathrm{D})$. Moreover, as in the case of vaginal infection, there was a significant decrease in the levels of $\mathrm{CD} 4^{+} \mathrm{T}$ cells in CVS when compared with $\mathrm{PB}$ (rectal infection weeks 2-9, $P=0.049-0.002$; oral infection weeks 1-6, $P=0.0016-0.0001)$. Regardless of the route of infection (vaginal, rectal, or oral) or type of inoculum (cell-free or cell-associated virus), there was a greater decrease in the levels of $\mathrm{CD} 4^{+} \mathrm{T}$ cells in the FRT and CVS in comparison to PB.

$\mathrm{HIV}$ infection results in increased numbers of human $\mathrm{CD}^{+}$and $C D 8^{+} T$ cells in CVS of BLT mice. As indicated above, HIV infection in humans and BLT mice results in a dramatic decrease in the levels of $\mathrm{CD} 4^{+} \mathrm{T}$ cells in the FRT and CVS that is not reflected in PB. In previous studies, no determination was made about whether the observed decrease in $\mathrm{CD}^{+}{ }^{+} \mathrm{T}$ cells in the FRT was due to a reduction in the number of $\mathrm{CD} 4^{+} \mathrm{T}$ cells and/or an increase in the number of $\mathrm{CD}^{+} \mathrm{T}$ cells $(33,49,50)$. To address this important question, we performed a longitudinal analysis of $\mathrm{CD} 4^{+}$and $\mathrm{CD} 8^{+}$ $\mathrm{T}$ cell numbers in CVS following HIV infection. Regardless of the route of exposure (vaginal, rectal, or oral) or type of inoculum, we observed significant increases in the numbers of both $\mathrm{CD} 4^{+}$and $\mathrm{CD}^{+} \mathrm{T}$ cells in CVS, albeit with different kinetics (Figure 5, A-C). Specifically, the increase in $\mathrm{CD} 4^{+} \mathrm{T}$ cells occurred during weeks 1-2 after infection and was somewhat modest (5- to 13-fold for each of the 3 exposure routes). In sharp contrast, the increase in the number of $\mathrm{CD} 8^{+} \mathrm{T}$ cells occurred later at weeks $2-7$ and was much greater (231-, 218-, and 56-fold after vaginal, oral, and rectal infections, respectively). These results demonstrate that the reduction in the percentages of $\mathrm{CD} 4^{+} \mathrm{T}$ cells observed in CVS of 

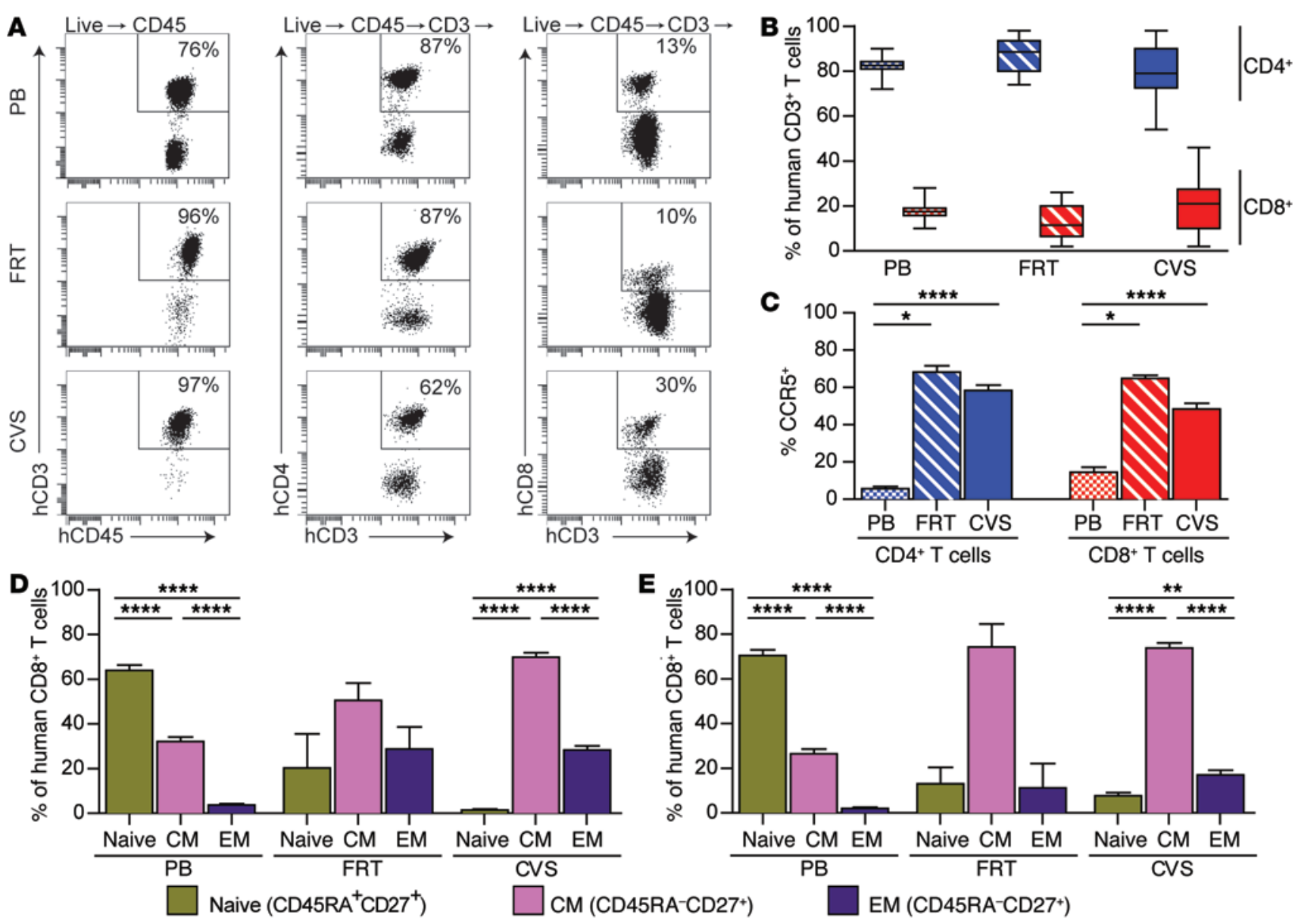

CD4+ $\mathrm{T}$ cells

Figure 2. Human memory T cells expressing CCR5 are the main human hematopoietic cell population in CVS and the FRT of BLT mice. (A) Flow cytometric analyses of cells from the PB, FRT, and CVS of a representative HIV- BLT mouse demonstrate reconstitution with human CD4 ${ }^{+}$and $C D 8^{+}{ }^{-}$cells in each compartment. (B and C) Further characterization of T cells in PB (dots), the FRT (diagonal stripes), and CVS (solid color). Box plot showing the percentages of $\mathrm{CD}_{4}^{+}$(blue) and CD8 ${ }^{+}$T cells (red) in PB $(n=60)$, the FRT $(n=6)$, and CVS $(n=57)$ of HIV- BLT mice. The middle line of the box plot is the median; box extends from the 25th to the 75th percentiles, and error bars extend down to the lowest value and up to the highest value (B). CD4+ and CD8 ${ }^{+} \mathrm{T}$ cells in PB $(n=9)$, the FRT ( $n=4)$, and CVS ( $n=46$, CD4 ${ }^{+}$T cells; $n=37$, CD8 ${ }^{+}$T cells) were analyzed for CCR5 expression with flow cytometry (C). (D and E) Bars represent mean values $\left( \pm\right.$ SEM). Further flow cytometric analyses characterizing the $\mathrm{CD}^{+}(\mathbf{D})$ and $C D 8^{+}(E)$ T cell subsets. Naive T cells $\left(C D 45 R A^{+} C D 27^{+}\right)$, green; CM T cells (CD45RA-CD27+), pink; and EM T cells (CD45RA-CD27-), purple. Bars represent mean values for PB $(n=26)$, the FRT ( $n=4)$, and CVS ( $n=60$, CD4 ${ }^{+}$ T cells; $n=41$, CD8 ${ }^{+}$T cells). Data represented as mean \pm SEM. A Mann-Whitney $U$ test with a Holm-Bonferroni step-down correction was used to compare the frequencies of immune cell populations within and between the PB, FRT, and CVS of BLT mice $\left({ }^{*} P<0.05,{ }^{* *} P<0.01,{ }^{* * *} P<0.0001\right)(\mathbf{C}-\mathbf{E})$.

HIV-infected BLT mice (Figure 4) was the result of a significant increase in the levels of $\mathrm{CD} 8^{+} \mathrm{T}$ cells present in the CVS.

ART efficiently suppresses HIV in CVS and restores $C D 4^{+}$and $C D 8^{+} T$ cell numbers. In order to examine the effect of ART on HIV levels and $\mathrm{CD} 4^{+}$and $\mathrm{CD} 8^{+} \mathrm{T}$ cell numbers in CVS, we treated infected mice with an ART regimen that consisted of TDF, emtricitabine (FTC), and raltegravir (RAL). This triple-drug combination has been shown to strongly suppress viral load in both humans and BLT mice with continuous dosing (51-53). However, ART discontinuation in patients results in a rapid rebound of plasma viremia as well as a loss of $\mathrm{PB} \mathrm{CD} 4^{+} \mathrm{T}$ cells $(54,55)$. These phenomena are also fully recapitulated in BLT mice $(53,56)$. In BLT mice infected vaginally with cell-associated virus (Supplemental Table 1), ART administration resulted in a dramatic and sustained decrease in viral load in both plasma and CVS as early as 2 weeks after ART initiation (Figure 6A). Analysis of $\mathrm{CD} 4^{+} \mathrm{T}$ cells in $\mathrm{PB}$ and $\mathrm{CVS}$ from these mice prior to ART demonstrated the characteristic steep decrease in the percentage of $\mathrm{CD} 4^{+} \mathrm{T}$ cells in CVS described above and the less pronounced decrease observed in PB. During ART, there was a dramatic increase in the percentage of $\mathrm{CD} 4^{+} \mathrm{T}$ cells in CVS and an increase in the percentage of $\mathrm{CD}^{+} \mathrm{T}$ cells in $\mathrm{PB}$ (Figure 6B). These findings are in agreement with the fact that $\mathrm{HIV}^{+}$ women on ART have a significantly higher percentage of cervical $\mathrm{CD} 4^{+} \mathrm{T}$ cells than infected women not receiving treatment (57). In addition - as indicated above - prior to treatment, there was a dramatic increase in total $\mathrm{CD} 8^{+} \mathrm{T}$ cells in CVS (Figure 6C). However, in response to ART, there was a rapid and substantial decrease in the numbers of $\mathrm{CD} 8^{+} \mathrm{T}$ cells in this compartment. In contrast, while the numbers of $\mathrm{CD} 8^{+}$cells decreased, the numbers of $\mathrm{CD} 4^{+}$ $\mathrm{T}$ cells increased, resulting in the eventual return to near-normal levels (Figure 6C). These results reveal that the observed increase in the percentage of $\mathrm{CD} 4^{+} \mathrm{T}$ cell in CVS during ART (Figure 6B) was caused by a concurrent decrease in the numbers of $\mathrm{CD}^{+} \mathrm{T}$ cells and an increase in the numbers of $\mathrm{CD} 4^{+} \mathrm{T}$ cells. 
A

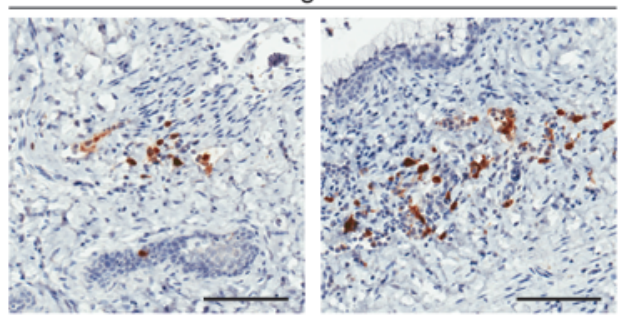

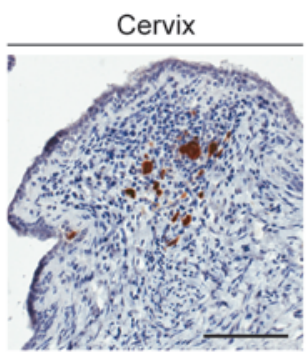

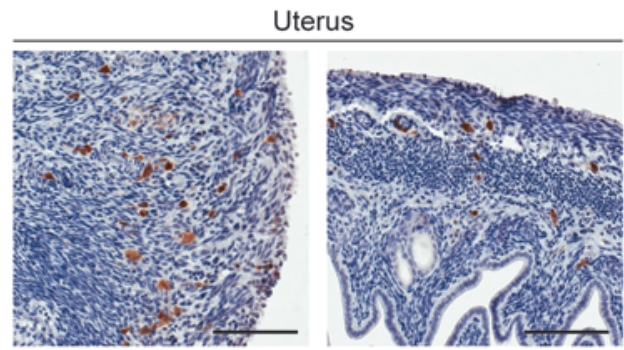

B

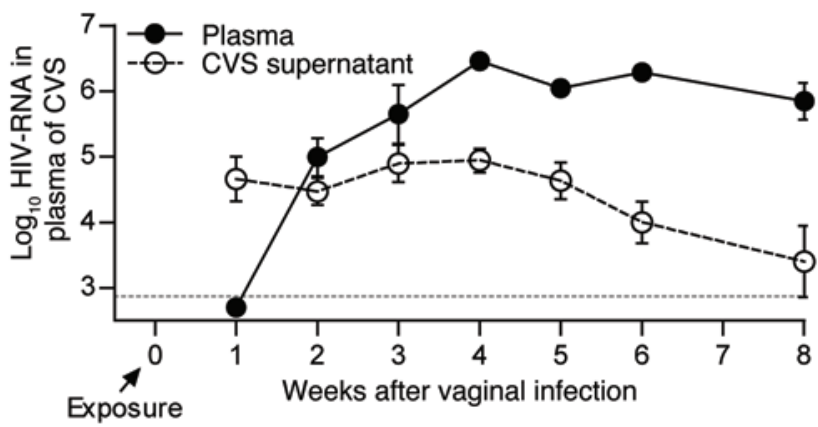

D

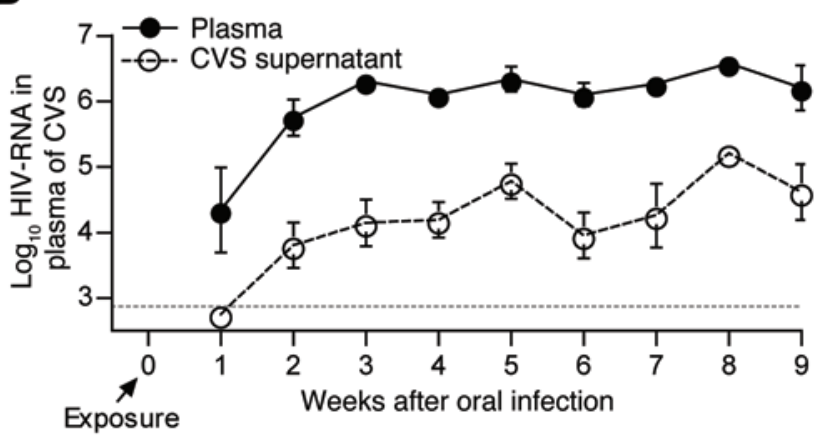

C

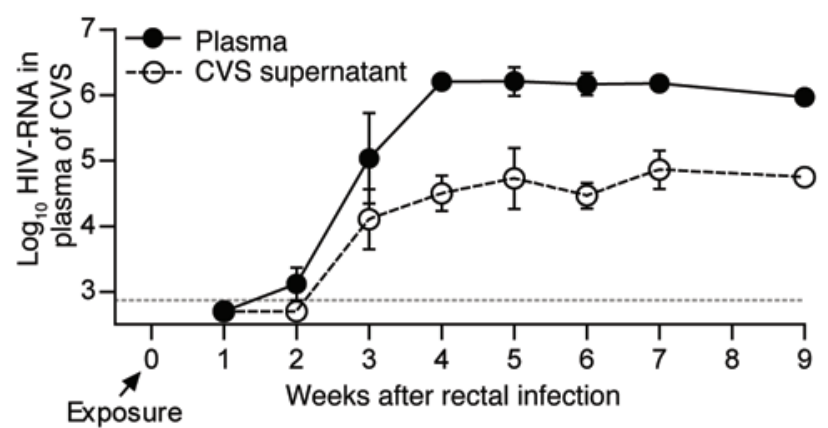

E

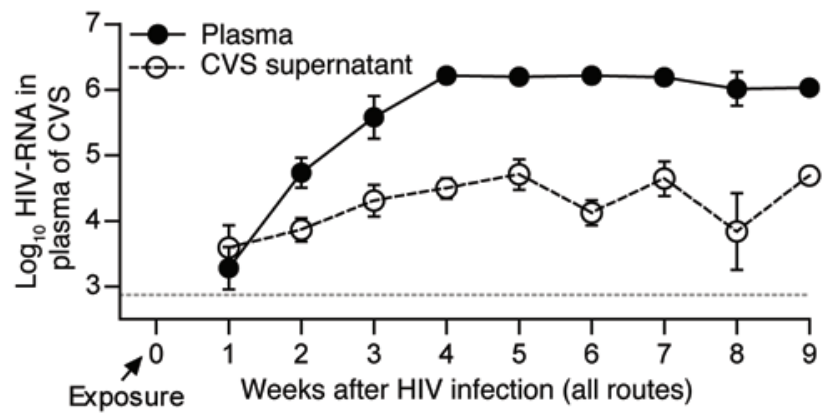

Figure 3. HIV is present in the FRT and CVS of infected BLT mice, and the kinetics of HIV-RNA in CVS is similar to the kinetics of HIV-RNA in PB plasma. (A) Immunohistochemical analysis of the FRT (vagina, cervix, and uterus) from one vaginally HIV-infected BLT mouse (3 weeks after exposure). HIV p24 gag-positive cells are stained brown. Scale bars: $100 \mu \mathrm{m}$. (B-D) HIV-RNA was detected in the plasma (black solid line, filled circles), and CVS supernatant (black dashed line, open circles) following vaginal (B) $(n=21)$, rectal (C) $(n=16)$, and oral (D) $(n=14)$ exposure. (E) Comparison of the viral load in plasma and CVS supernatant of all routes combined (mice infected vaginally, rectally, and orally combined; $n=51$ ). The assay limit of detection is indicated with a dashed gray line. (B-E) Data represented as mean \pm SEM. Associations between plasma and CVS supernatant viral loads were estimated with Spearman's correlation coefficient.

We next determined if ART suppression of cell-free HIV-RNA levels observed in plasma and CVS (Figure 7A) parallels a similar decrease in the levels of cell-associated HIV in PB, CVS, and the FRT. For this purpose, we isolated cells from PB, FRT, and CVS and analyzed their levels of cell-associated HIV-RNA (Figure 7B). Our results show that ART significantly decreased the amount of cell-associated HIV-RNA in all 3 compartments (PB ART vs. No ART, $P=0.0009$; FRT ART vs. No ART, $P=0.0002$; and CVS ART vs. No ART, $P=0.015$ ) (Figure $7 \mathrm{~B}$ ). However, cell-associated HIVRNA remained readily detectable in the FRT and/or CVS of the majority of mice undergoing ART. Therefore, despite the strong reduction in the levels of cell-free HIV-RNA in mice receiving ART, our analysis reveals an important dichotomy between the suppression of cell-free HIV-RNA levels observed in CVS and the continued presence of residual levels of cell-associated HIV-RNA in the FRT/CVS. To determine whether these residual HIV-RNA ${ }^{+}$ cells constitute an important source of infectious virus, we established a sensitive coculture assay to measure the number of infectious cells in PB, CVS, and the FRT of infected mice receiving ART (Figure 7, C and D). Our results showed (i) that infectious cells were readily detected in $\mathrm{PB}, \mathrm{CVS}$, and the FRT of infected BLT mice; (ii) that ART suppresses the number of infectious cells in each of these 3 compartments; and (iii) that this reduction was statistically significant $(P=0.04)$ (Figure 7D). Thus, our results demonstrate that ART efficiently suppresses levels of cell-free HIV and infectious cells in PB, CVS, and the FRT. Most importantly, we then determined if ART suppresses the number of HIV-RNA ${ }^{+}$cells in the PB, CVS, and FRT of BLT mice to levels below those needed to prevent secondary mucosal HIV transmission. We assessed the ability of HIV-infected cells to establish infection in vivo by vaginally exposing BLT mice to 2 different doses of HIV-infected PB mononuclear cells (PBMCs) and monitoring their plasma level of HIV-RNA for 
A

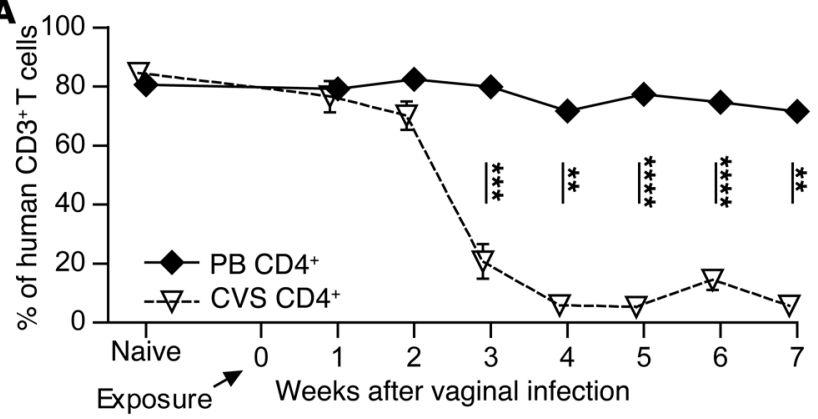

C

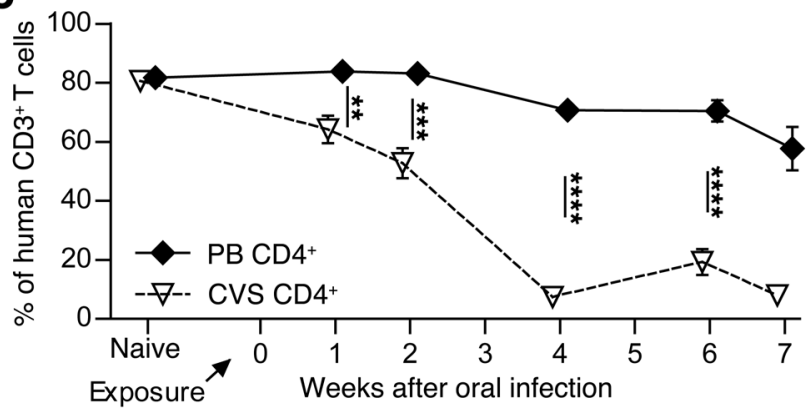

B

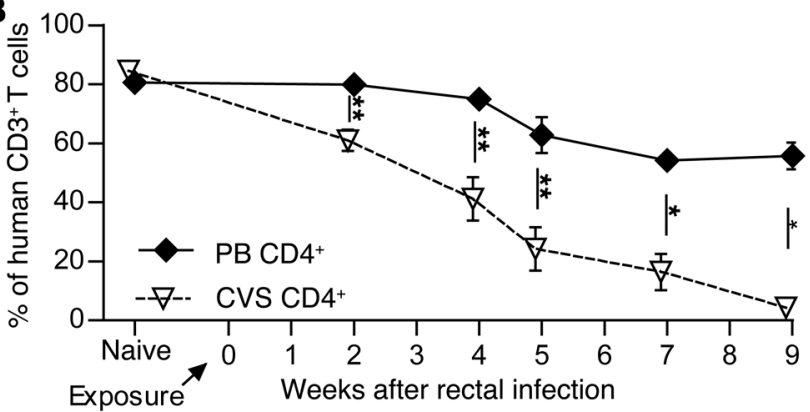

D

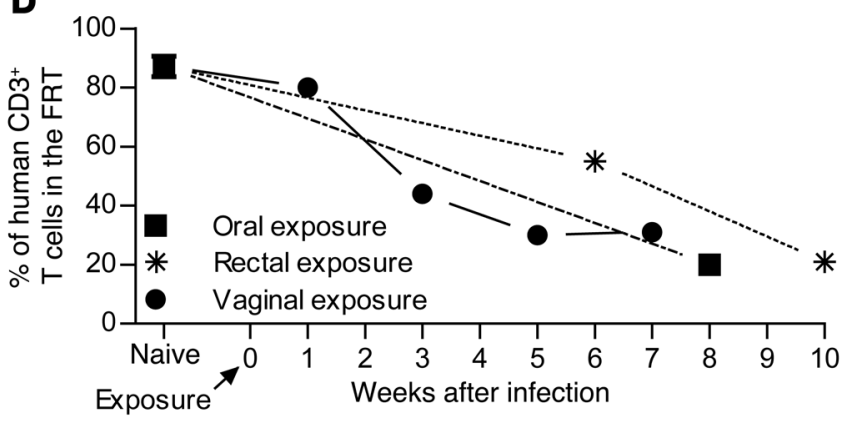

Figure 4. After vaginal, rectal, or oral HIV infection, there is a decrease in the percentage of CD4 ${ }^{+}$T cells in CVS and the FRT. (A-C) The percentage of CD4 ${ }^{+}$T cells in PB (filled diamond, solid line) and CVS (open triangle, dashed line) was measured in HIV- $(n=28)$ and vaginally (A) ( $\left.n=18\right)$, rectally (B) $(n=11)$, or orally (C) $(n=12)$ infected BLT mice. Data is shown as mean \pm SEM. A Mann-Whitney $U$ test was used to compare CD4+ T cell levels between the PB and CVS $\left({ }^{*} P<0.05\right.$, ${ }^{* *} P<0.01,{ }^{* *} P<0.001$, $\left.{ }^{* * *} P<0.0001\right)$. (D) Additional analysis of the percentage of CD4+ ${ }^{*}$ cells in the FRT was performed in HIV- BLT mice $(n=7)$; vaginally infected BLT mice (filled circle) at weeks $1(n=1), 3(n=1), 5(n=1)$, and $7(n=1)$; rectally infected mice (asterisk) at weeks $6(n=2)$ and $10(n=1)$; and an orally infected mouse (filled square) at week $8(n=1)$ after exposure.

8 weeks. As shown in Figure 7E, all BLT mice exposed to 5,000 HIV-infected PBMCs remained negative for HIV-RNA. However, $50 \%$ of mice exposed to $10,000 \mathrm{HIV}$-infected cells became positive for plasma HIV-RNA. Our results revealed that the number of HIV-RNA ${ }^{+}$cells in all 3 compartments analyzed from ARTsuppressed BLT mice is well below what is needed to establish vaginal HIV transmission in this model.

\section{Discussion}

In this manuscript, we provide data demonstrating (i) that regardless of the route of infection (vaginal, rectal, or oral) and whether the inoculum is cell-free or cell-associated HIV, local viral replication occurs in the FRT and CVS during acute HIV infection, the time when secondary transmission is most likely to occur (Figure 3); (ii) that this is followed by a transient increase in $\mathrm{CD}^{+} \mathrm{T}$ cell levels in CVS that can serve to provide additional target cells to sustain or promote infection (Figure 5); and (iii) that this is itself followed by a somewhat delayed increase in $\mathrm{CD}^{+} \mathrm{T}$ cell levels in CVS (Figure 5). In addition, our study provides in vivo evidence supporting the hypothesis behind the success of HPTN 052 (12): that initiating ART can reduce the risk of secondary HIV transmission by efficiently suppressing HIV levels in the genital tract (Figures 6 and 7).

Interestingly, our results also highlighted a potentially important dichotomy between the levels of cell-free virus and cellassociated HIV-RNA in the FRT and CVS of ART-suppressed mice. Specifically, in animals with undetectable cell-free HIVRNA in plasma and CVS, significant levels of HIV-infected cells producing viral RNA remain in the FRT and CVS of some ARTtreated mice (Figure 7). The presence of cell-associated HIV-RNA has been demonstrated in other secretions of ART-suppressed women. Valea et al. demonstrated the presence of cell-associated HIV-RNA in breast milk obtained from ART-treated mothers with undetectable levels of cell-free HIV-RNA in plasma and breast milk (58). These results are in agreement with our observations in BLT mice demonstrating that cell-associated HIV-RNA can persist in mucosal secretions despite ART. Collectively, our results and those of Valea et al. may have important implications for the design of effective HIV prevention and curative approaches. In the future, it will be important to determine if cell-associated HIV-RNA persists in other mucosal secretions and tissues despite suppression of cell-free HIV-RNA.

Worldwide, the majority of new HIV infections occur after heterosexual exposure (59). In vaginally exposed women, the primary ports of HIV entry are the mucosal surfaces of the vagina, cervix, and uterus (60-62). The identity and the location of the initial cells involved in HIV-1 transmission are a subject of great debate (29). The DC-T cell milieu is a highly permissive site for virus growth, and DCs likely contribute to driving the productive infection in $\mathrm{CD}^{+} \mathrm{T}$ cells $(63-67)$. Hence, both intraepithelial Langerhans cells and DCs have potential important roles in vaginal HIV transmission (65-69). However, the mucosa of the human FRT contains an abundance of $\mathrm{CD}^{+}$ T cells $(24,25,34,68)$, and experiments in both NHPs (nonhuman primates) and human explant models suggest that the first productively infected cells are likely T cells $(61,68,70-73)$. 


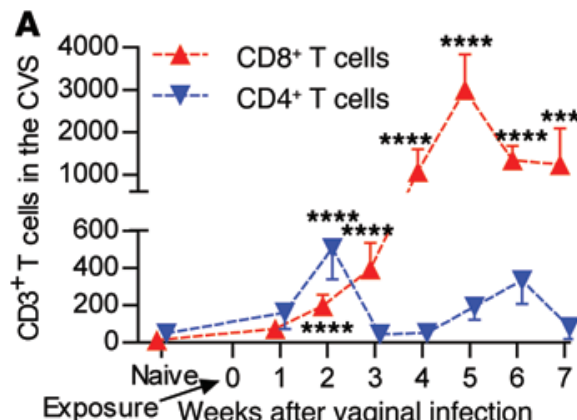

Exposure Weeks after vaginal infection
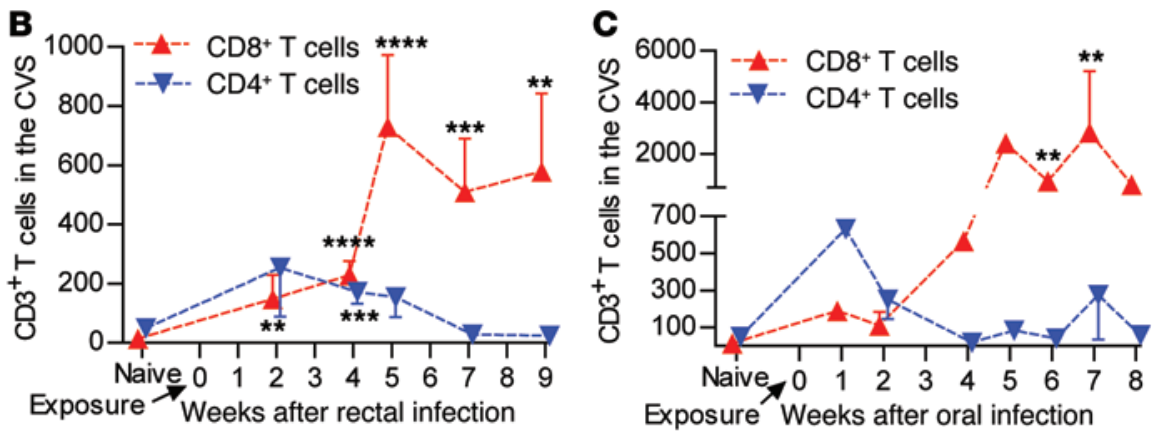

Figure 5. After vaginal, rectal, or oral HIV infection, there is an increase of CD8+ and CD4+ $\mathbf{T}$ cells in CVS. (A-C) The CD8 ${ }^{+}$(filled upward triangle, dashed red line) and CD4+ T cell numbers (filled downward triangle, blue dashed line) in CVS were measured in HIV- $(n=28)$ and vaginally $(\mathbf{A})$ ( $n=18)$, rectally (B) $(n=11)$, or orally $(C)(n=4)$ infected BLT mice. Data presented as mean \pm SEM. Statistical analysis represents comparisons of the weeks indicated vs. the numbers of CD4 $4^{+}$or $C D 8^{+} T$ cells in naive mice. A Mann-Whitney $U$ test was used to compare the numbers of CD4 ${ }^{+}$and $C D 8^{+} T$ cells in the CVS of naive and HIV-infected BLT mice $\left({ }^{* *} P<0.01,{ }^{* * *} P<0.001,{ }^{* * *} P<0.0001\right)$.

Regardless, each of the most relevant human HIV target cells $\left(\mathrm{CD} 4^{+} \mathrm{T}\right.$ cells, macrophages, and DCs) are present throughout the entire FRT of BLT mice (Figure 1, Supplemental Figures 1 and 2, and ref. 21). Reconstitution of the FRT of BLT mice with the appropriate human hematopoietic cells renders BLT mice susceptible to vaginal HIV transmission (21). The susceptibility of BLT mice to vaginal HIV infection has allowed this model to be used to evaluate novel approaches of $\operatorname{HIV}$ prevention $(21,23,74)$.

In this manuscript, we utilized BLT mice to elucidate and study critical events occurring in the FRT and CVS during HIV infection. Specifically, by performing comprehensive analyses of the $\mathrm{T}$ cell subsets present in the FRT and CVS, we have gained insight into the human immune cell populations in this organ. Consistent with observations made in healthy women, the majority of the human lymphocytes present in both the FRT and CVS of BLT mice are memory T cells (Figure 2D and refs. 31, 32). Also, consistent with the preferential vaginal transmission of CCR5-tropic viruses, a high percentage of $\mathrm{CD}^{+} \mathrm{T}$ cells present in the FRT and CVS express CCR5 (Figure 2C and refs. 31, 32). Furthermore, consistent with humans, a significant number of the memory $\mathrm{CD} 4^{+} \mathrm{T}$ cells present in the FRT and CVS of BLT mice expressed $\alpha 4 \beta 7$ (Supplemental Figure 3). The similarities between the phenotypes of hematopoietic cells present in the FRT of humans and BLT mice emphasize the utility of BLT mice as an in vivo model for the study of events occurring at the site where HIV exposure occurs.

Our results demonstrating parallel reductions in the percentage of $\mathrm{CD}^{+} \mathrm{T}$ cells in the FRT and CVS of BLT mice indicate that the cell populations are closely linked throughout the course of infection (Figure 4). These striking similarities between the dynamics of T cells present in CVS and the FRT after HIV infection suggest that cells from CVS could be potentially used as a surrogate for monitoring some of the changes that occur in the FRT. Thus, these results may have significant implications that could facilitate and simplify future studies of transmission and prevention in both humans and in NHP models by minimizing the need to harvest or biopsy the FRT.

In order to study the dynamics of human $\mathrm{CD} 4^{+}$and $\mathrm{CD} 8^{+} \mathrm{T}$ cells and viral replication that occur in the FRT after vaginal HIV infection, we vaginally exposed BLT mice to HIV. Our results demonstrate an increase of $\mathrm{CD}^{+} \mathrm{T}$ cells in CVS during the first
2 weeks after infection (Figure 5A), providing additional HIV target cells to sustain and potentially spread the initial infection. These results are consistent with HIV-RNA being present in CVS within 1 week after exposure (Figure 3B), suggesting that local HIV replication occurs in the FRT and/or CVS followed by the establishment of systemic infection in all mice by 2 weeks after exposure (Figure 3B). Especially noteworthy is the timing of viral shedding into CVS after vaginal exposure, which is characterized by an early peak in viremia followed by a gradual decline (Figure 3B) that mimics the HIV genital shedding profile observed in CVS of women during acute HIV infection (39). Notably, we also observed an increase in $\mathrm{CD}^{+} \mathrm{T}$ cells in CVS after vaginal infection (Figure 5A). However, in contrast to the increase of $\mathrm{CD} 4^{+}$cells occurring within one to 2 weeks after exposure, the increase of $\mathrm{CD} 8^{+} \mathrm{T}$ cells was first detected 2 weeks after exposure and did not peak until week 5-7 (Figure 5A). These results are consistent with reports from vaginal-infection studies in NHPs demonstrating that initial SIV infection takes place in a few $\mathrm{CD}^{+}$ $\mathrm{T}$ cells, resulting in local inflammation and recruitment of additional CD $4^{+} \mathrm{T}$ cells $(61,72,75)$. Clusters of SIV-infected cells are present within inflammatory infiltrates, which increase in size during days $4-10$ after exposure $(61,72,75)$. In addition, genital $\mathrm{CD}^{+} \mathrm{T}$ cell influx was detected $2-3$ weeks after vaginal SIV infection of NHPs, a time by which all animals had become systemically infected $(72,76)$. Thus, the timing of $\mathrm{CD}^{+}$and $\mathrm{CD} 8^{+}$ $\mathrm{T}$ cell increase in CVS, as well as the timing of local viral replication and systemic infection that we have observed in BLT mice, is strikingly similar to NHPs. Together, these results support the hypothesis that the increase of $\mathrm{CD}^{+} \mathrm{T}$ cells in the CVS/FRT is delayed after exposure, potentially preventing effective suppression of HIV replication at early stages after exposure $(75,76)$.

We next investigated the effect of ART on HIV levels in CVS of BLT mice. Consistent with results obtained in humans, ART treatment of infected BLT mice resulted in a significant decrease in the levels of HIV in both PB and CVS $(15,16)$. However, our finding showing the absence of cell-free HIV in CVS during ART, concurrent with the continued presence of infected cells producing HIV-RNA, could have important implications for HIV prevention and eradication strategies. Consistent with the lack of transmission observed in heterosexual couples where the infected partner is undergoing 

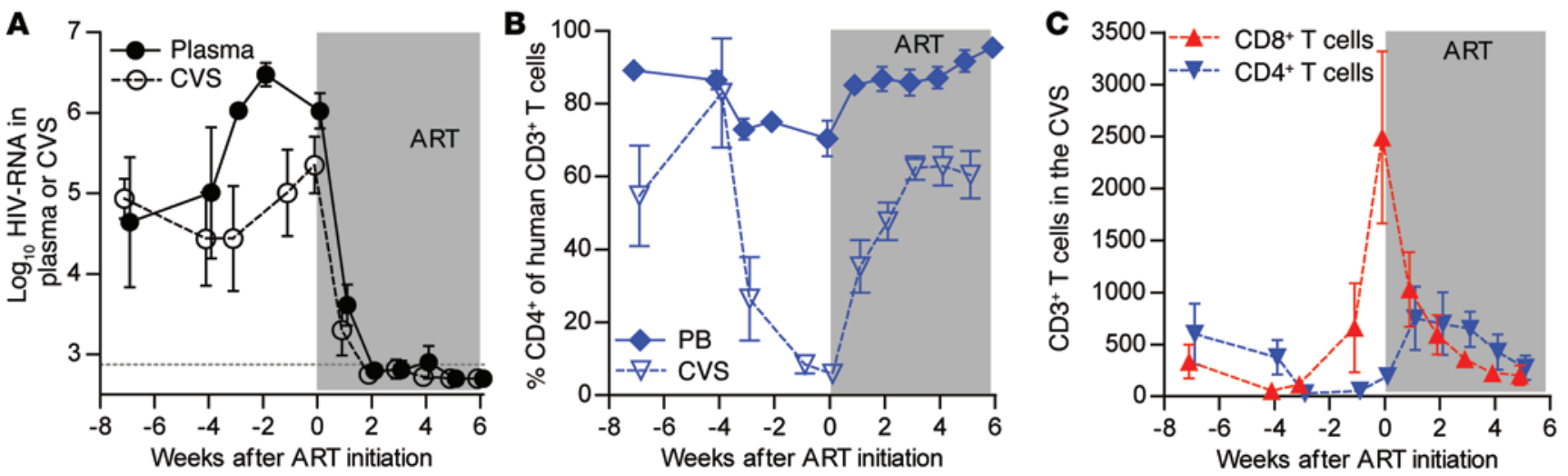

Figure 6. ART suppresses HIV-RNA in the plasma and CVS, leading to a reduction in the number of CD8 ${ }^{+} \mathrm{T}$ cells and an increase of CD4 ${ }^{+} \mathrm{T}$ cells in CVS. Six HIV-infected BLT mice were treated with daily ART consisting of FTC, TDF, and RAL to evaluate the effect of ART on HIV-RNA levels in the plasma and CVS supernatant, as well as T cell levels in PB and CVS. ART was initiated in BLT mice $6-8$ weeks after HIV exposure. Time point 0 corresponds to the day of ART initiation, and the time points corresponding to ART are shaded gray. (A) Viral load analyses of the plasma (black solid line, filled circles) and CVS supernatant (black dashed line, open circles). The assay limit of detection is indicated with a dashed gray line. (B) The percentage of CD4+ cells in PB (filled diamond, blue solid line) and CVS (open downward triangle, blue dashed line). (C) The number of CD4+ (filled downward triangle, blue dashed line) and CD8+ (filled upward triangle, dashed red line) T cells in CVS. Data represented as mean \pm SEM.

ART (12), our analysis showed that the residual levels of HIV-RNA ${ }^{+}$ cells present in mice receiving ART were too low to transmit HIV in vitro. This lack of HIV transmission could have been due to too few infected cells for cell-to-cell transmission and/or too little cell-free replication-competent virus produced from the residual HIV-RNA ${ }^{+}$ cells for in vitro infection of target cells. The residual levels of HIV$\mathrm{RNA}^{+}$cells detected in the CVS and FRT of ART-suppressed mice were well below the number of HIV-infected cells required for HIV transmission in BLT mice. The availability of a small animal model that so accurately recapitulates key aspects of the human condition represents a unique tool for the in vivo study of the intricate cellular dynamics occurring during HIV infection in the FRT and to address critical questions in the field, such as whether cell-to-cell transmission contributes sexual transmission of HIV or whether all transmission is via cell-free, replication-competent virions. In addition, this model could prove helpful in the evaluation of novel approaches to prevent cell-free and cell-associated HIV transmission.

\section{Methods}

\section{Generation of BLT mice}

BLT mice were prepared essentially as previously described (19-23). Briefly, BLT mice were individually bioengineered by transplanting (BM transplant) human fetal liver-derived $\mathrm{CD} 34^{+}$hematopoietic stem cells into NOD/SCID $/ \gamma \mathrm{c}^{-/-}$mice (stock number 00557, NSG mice; The Jackson Laboratory) implanted with autologous human liver and thymus tissue (Advanced Bioscience Resources). A sandwich of 1- to 2-mm pieces of human thymus-liver-thymus tissue was implanted under the kidney capsule of 6- to 14-week-old female NSG mice. Mice were exposed to sublethal $\gamma$ irradiation (300 cGy) 4-24 hours prior to the transplantation of $\mathrm{CD} 34^{+}$stem cells $\left(2.5-8 \times 10^{5}\right.$ $\mathrm{CD}^{+} 4^{+}$cells) to facilitate $\mathrm{BM}$ engraftment.

\section{Immunohistochemical analyses}

Immunohistochemical analyses were performed on paraffinembedded FRT sections. FRTs for IHC were harvested from BLT mice, fixed in $4 \%$ paraformaldehyde overnight at $4^{\circ} \mathrm{C}$, embedded in paraffin, cut into 5 - $\mu \mathrm{m}$ sections, and mounted onto poly-L-lysinecoated glass slides. Following paraffin removal, antigen retrieval (Diva Decloaker, Biocare Medical), and blocking of nonspecific Ig-binding sites (Background Sniper, Biocare Medical), tissue sections were stained with primary antibodies overnight at $4^{\circ} \mathrm{C}$ and developed with a biotin-free HRP-polymer system (MACH3 Mouse HRPPolymer Detection, Biocare Medical). All tissue sections were treated with HRP substrate (ImmPACT DAB, Vector Laboratories) and then counterstained with hematoxylin. Primary antibodies specific for human CD4 (clone 1F6, Leica Biosystems), human CD68 (clone KP1, Dako), and human CD11c (clone 5D11, Leica Biosystems) were used to identify human cells $(24,77-81)$. HIV-infected cells were detected with an antibody directed against HIV p24 gag (clone Kal-1, Dako). As a control, tissue sections were stained with the following isotype control antibodies: mouse IgG1 (clone DAK-G01, Dako) and mouse IgG2a (clone DAL-G02, Dako). The stained sections were scanned by ScanScope CS (Aperio, Leica Biosystems) and the images were then analyzed by ImageScope (Aperio, Leica Biosystems).

\section{Flow cytometric analyses}

Flow cytometric analyses were performed on PB, FRT, and CVS cells. CVS samples were obtained by performing a cervicovaginal lavage with sterile PBS (3 washes of $20 \mu \mathrm{l}$ each, $\sim 60 \mu \mathrm{l}$ total volume). To ensure that the procedure was atraumatic, cervicovaginal lavages were performed with $20 \mu \mathrm{l}$ or $200 \mu \mathrm{l}$ sterile filter pipet tips that were inserted no more than 3-5 $\mathrm{mm}$ into the vaginal cavity. Following centrifugation in a microcentrifuge ( $300 \mathrm{~g}$ for 5 minutes), CVS cell-free supernatants were used for HIV-RNA analyses and the cell pellets were used for flow cytometric analyses. The CVS samples contained a highly variable number of total cells (due to variable cell shedding). Therefore, the human $\mathrm{CD}^{+} \mathrm{T}$ cell numbers in CVS were normalized to 100,000 total cells. FRTs were harvested and digested, and single cell suspensions were isolated as previously described (23). BLT mice were monitored for levels of human hematopoietic cells $\left(\mathrm{CD} 45^{+}\right)$ in PB by flow cytometry, as we have previously described (19-23). 

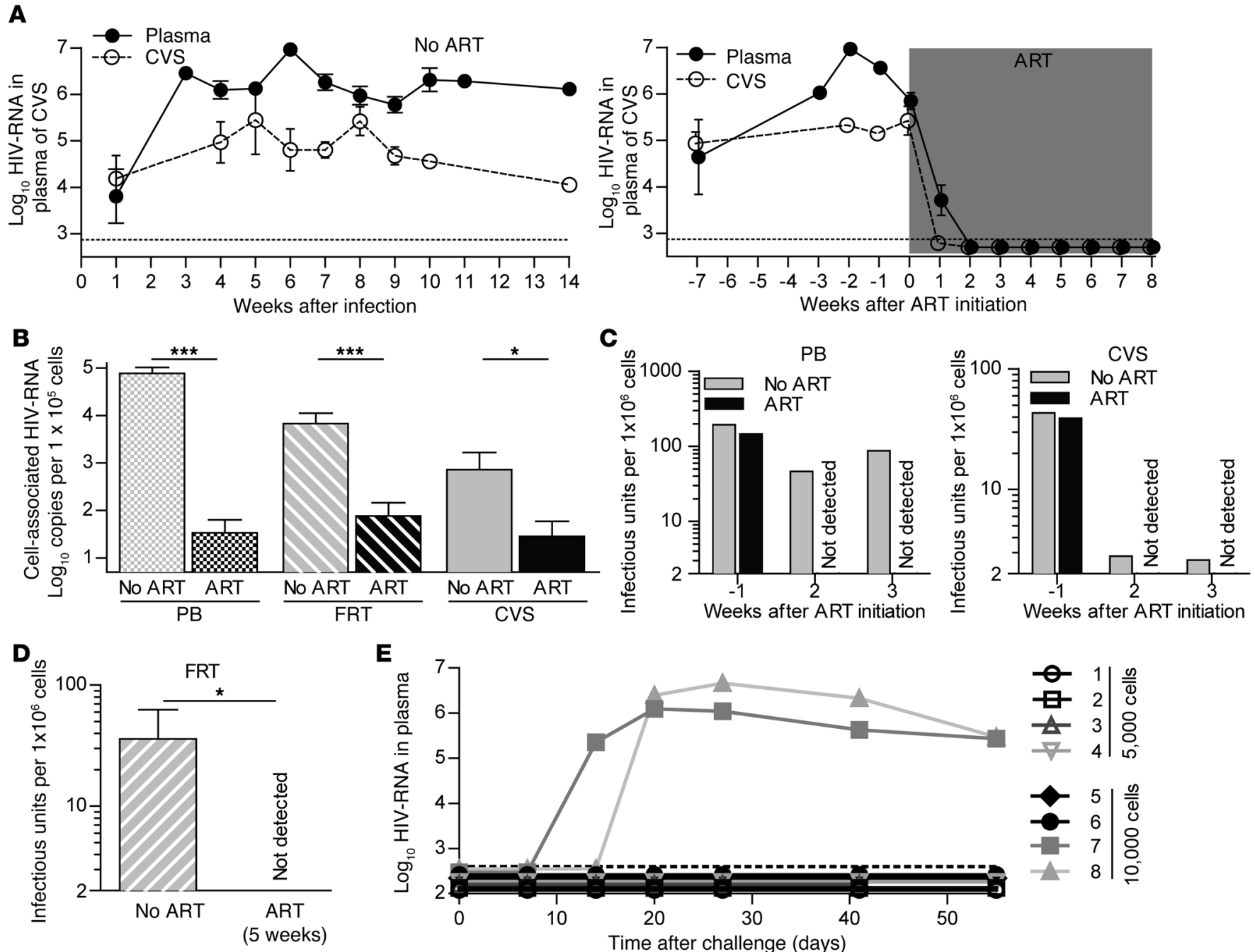

Figure 7. ART suppresses cell-free HIV-RNA in CVS and PB but does not consistently suppress cell-associated HIV-RNA in the FRT and CVS. (A) Viral load analyses of the plasma (black solid line, filled circles) and CVS supernatant (black dashed line, open circles) demonstrated sustained viral load in the plasma and CVS supernatant of 8 HIV-infected ART-naive mice (left panel) and a dramatic decrease in viral load to undetectable levels in both plasma and CVS supernatant in 5 representative ART-treated mice (right panel). Time points corresponding to ART are shaded gray. (B) Cell-associated HIV-RNA in the PB, FRT, and CVS of mice receiving ART for $5-8$ weeks $(n=8)$ and of ART-naive mice (No ART) $(n=8)$. RNA was isolated from mononuclear cells, and the RNA determination for each sample was performed in triplicate. (C) The level of infectious cells in PB and CVS from BLT mice was determined in 8 ART-treated mice and 5 ART-naive mice. Samples from all mice in each group (ART vs. No ART) were pooled at each time point: week -1 (ART $n=8$, No ART $n=5$ ), week 2 (ART $n=4$, No ART $n=5$ ), and week 3 (ART $n=3$, No ART $n=5$ ). (D) The level of infectious cells in the FRT of mice treated with ART for 5 weeks and in ART-naive mice (ART $n=4$, No ART $n=5$ ). (B-D) Bars represent mean values. Data are represented as \pm SEM. (C and D) Limit of detection was 2 infectious units per $1 \times 10^{6}$ cells. (E) BLT mice were exposed vaginally to 2 different doses of HIV-infected PBMC (open symbols: 5,000 PBMC, $n=4$; closed symbols: 10,000 PBMC, $n=4$ ). Plasma levels of HIV-RNA were monitored for 8 weeks. A Mann-Whitney $U$ test was used to compare levels of cell-associated HIV-RNA and infectious cells between ART-naive and ART-treated mice $\left({ }^{*} P<0.05,{ }^{* * *} P<0.001\right)(\mathbf{B}$ and $\mathbf{D})$. The assay limit of detection is indicated with a dashed gray line.

The antibody clones included in the flow cytometry panels that were used to analyze PB and cells isolated from the FRT and CVS of BLT mice are as follows: Panel A - CD3 FITC (HIT3a), CD4 PE (RPA-T4), CD8 PerCP (SK1), and CD45 APC (HI30); Panel B - CD8 FITC (SK1), CXCR4 PE (12G5) or IgG2 $\alpha$ PE (G155-178), CD4 PerCP

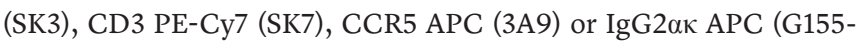
178), and CD45 APC-Cy7 (2D1); Panel C - CD45RA FITC (HI100) or IgG2 FITC (27-35), CD27 PE (M-T271) or IgG1к PE (MPOC-21), CD8 PerCP (SK1), CD3 PE-Cy7 (SK7), CD45 APC (HI30), and CD4 APC-H7 (RPA-T4); Panel D - CD27 FITC (M-T271) or IgG1k FITC (MOPC-21), $\alpha 4 \beta 7$ PE (ACT-1) or IgG1k PE (P3.6.2.8.1), CD8
PerCP (SK1), CD3 PECy7 (SK7), CD45 APC (H130), CD4 APC-H7 (RPA-T4), and CD45RA Pacific Blue (F8-11-13) or IgG1k Pacific Blue (MOPC-21). All antibodies were purchased from BD Biosciences, except for CD45RA Pacific Blue (AbD Serotec), unconjugated IgG1k (eBioscience), and unconjugated $\alpha 4 \beta 7$ (ACT-1, catalog 11718) (NIH AIDS Research and Reference Reagent program) (82). The unconjugated $\alpha 4 \beta 7$ (ACT-1) and isotype IgG1k antibodies were labeled with PE using the LYNX Rapid RPE antibody conjugation kit (AbD Serotec). Gates defining CD27, CD45RA, CCR5, and $\alpha 4 \beta 7$ expression were set with isotype-matched fluorophore-conjugated antibodies. In Figure 2B, to account for the differential presence of NKT cells 
that are $\mathrm{CD}^{+}$but lack expression of CD4 and CD8, the percentage of $\mathrm{CD}^{+}$and $\mathrm{CD} 8^{+} \mathrm{T}$ cells in $\mathrm{PB}, \mathrm{CVS}$, and FRT was calculated by dividing the number of $\mathrm{CD}^{+} \mathrm{T}$ cells that expressed CD4 or CD8 by the total number of $\mathrm{CD}^{+} \mathrm{T}$ cells that expressed either $\mathrm{CD} 4$ or $\mathrm{CD} 8$. Flow cytometric data collection and analyses were performed using a BD FACS Canto or Fortessa cytometer and FACSDiva software.

\section{Exposure of BLT mice to HIV and treatment with ART}

BLT mice were infected vaginally, rectally, or orally with cell-free or cell-associated CCR 5 tropic HIV-1 essentially as previously described (19-23, 45, 47).

Cell-free HIV exposures. Stocks of HIV-1 $1_{\text {IR-CSF }}$ or HIV-1 $1_{\text {RHPA }}$ were prepared and tittered using TZM-bl cells (AIDS Research and Reference Reagent Program, Division of AIDS, National Institute of Allergy and Infectious Diseases) as previously described (19-23). BLT mice were exposed vaginally to $3 \times 10^{5}-3.5 \times 10^{5}$ tissue culture infectious units (TCIU), rectally to $3.5 \times 10^{5}-4.8 \times 10^{6} \mathrm{TCIU}$, or orally to $1.4 \times 10^{6} \mathrm{TCIU}$ of HIV-1.

Cell-associated HIV exposures. Human PBMCs were infected in vitro with HIV-1 $1_{\text {JR-CSF }}$ PBMCs were cultured in the presence of IL-2 and PHA for 3 days and then inoculated at a MOI of 0.1 with HIV$1_{\text {JR-CSF }}$ by a 2-hour spin infection. Next, PBMCs were washed 3 times, resuspended in IMDM medium, and - 3-4 days after inoculationthe percentage of HIV-infected cells was determined by intracellular staining for p24 gag (clone KC57-FITC, Beckman-Coulter) using the Fix and Perm kit (Invitrogen). BLT mice were vaginally exposed

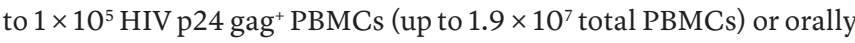
to $3.75 \times 10^{5} \mathrm{HIV}$ p24 $\mathrm{gag}^{+} \mathrm{PBMCs}$ (up to $1.6 \times 10^{7}$ total PBMCs). Vaginal exposure to cell-associated HIV was performed by administering 5,000 or 10,000 HIV-1 p24+ cells in a volume of $10 \mu \mathrm{l}$ to anesthetized BLT mice. We did not observe any phenotypic differences when using HIV-1 $1_{\mathrm{JR}-\mathrm{CSF}}$ or HIV-1 $1_{\mathrm{RHPA}}$ for exposures or when using cell-free virus versus cell-associated virus. HIV-infected BLT mice designated for treatment received daily ART (by i.p. injection) consisting of FTC (140-200 mg/kg body weight), tenofovir disoproxil fumarate (TDF; 146-208 mg/kg), and RAL (56-80 mg/kg), as we have previously described (53). ART was administered for an average of 5.6 weeks (range 4-8 weeks). No overt drug-associated toxicity was observed.

\section{Real-time PCR for HIV-RNA}

Infection of BLT mice with HIV was monitored in plasma and CVS supernatant by determining levels of cell-free HIV-RNA using one-step quantitative PCR (qPCR) (ABI custom TaqMan Assaysby-Design) according to the manufacturer's instructions (primers [5'-CATGTTTTCAGCATTATCAGAAGGA-3' and 5'-TGCTTGATGTCCCCCCACT-3'] and MGB-probe [5'FAM-CCACCCCACAAGATTTAAA CACCATGCTAA-Q 3' (83)]) as previously described, with a limit of detection of 750 HIV-RNA copies per $\mathrm{ml}$ (53). The lower sensitivity of our standard assay compared with that of the standard clinical assay (50 copies per $\mathrm{ml}$ ) is due to the lower volume of plasma that can be obtained routinely from mice. The levels of cell-associated HIV-RNA were analyzed in mononuclear cells isolated from PB, FRT, and CVS. HIV-RNA was extracted from mononuclear cells (RNeasy Mini Kit, QIAGEN), and a one-step qPCR was performed as described above. For all analyses, cell-free and cell-associated HIV-RNA measures were $\log _{10}$ transformed.

\section{Replication competence of HIV in cells from the PB, CVS, or FRT of infected BLT mice}

The replication competence of virus present in cells obtained from infected BLT mice was determined using a coculture assay. For this purpose, cells isolated from $\mathrm{PB}$, CVS, or the FRT of infected animals were cocultured with TZM-bl indicator cells in the presence of DEAE-dextran (Sigma-Aldrich) $(2 \mu \mathrm{g} / \mathrm{ml})$ for 24 hours. The culture medium was then removed and replaced with fresh medium. Cells were incubated for an additional 48 hours, fixed, and stained for $\beta$-galactosidase activity. Individually infected cells were manually counted under an inverted microscope. The limit of detection was two infectious units per $1 \times 10^{6}$ cells.

\section{Statistics}

Bivariate statistical comparisons were performed using the 2-sample Mann-Whitney $U$ test. The Bonferroni step-down (Holm) correction was used to adjust for multiple testing for sets of related hypothesis tests in Figure 2 and Supplemental Figure 3. Data in Figure 2 and Supplemental Figure 3 were analyzed as independent observations. Some of the PB and CVS data in Figure 2 represent multiple longitudinal time points from the same animal (Figure 2, B, D, and E) and/ or paired observations (Figure 2, B-E). In addition, some of the $\mathrm{PB}$ data in Supplemental Figure 3 represent multiple longitudinal time points from the same animal and/or are paired with CVS and/or FRT data. Collectively, PB and CVS data were obtained from 30 mice for Figure 2B ( $n=30, \mathrm{~PB} ; n=30, \mathrm{CVS}), 20$ mice for Figure 2C $(n=9, \mathrm{~PB}$; $n=19, \mathrm{CVS}), 29$ mice for Figure 2D ( $n=9, \mathrm{~PB} ; n=26, \mathrm{CVS})$, and 18 mice for Figure $2 \mathrm{E}$ ( $n=9, \mathrm{~PB} ; n=15$, CVS). The data in Supplemental Figure 3 represents a total of $21 \mathrm{BLT}$ mice $(n=16, \mathrm{~PB} ; n=13$, CVS; and $n=5$, FRT). Associations between viral load in plasma and CVS supernatant were estimated with Spearman's correlation coefficient. Correlation estimates were calculated at each time point, and an average correlation was computed by taking a weight average of time-specific estimates (84). The bootstrap (85) was used to calculate CIs for the average correlation and to assess whether the average correlation was nonzero. Analyses were conducted using R version 2.13, GraphPad Prism version 5.0, and SAS version 9.4. $P<0.05$ were considered significant. Statistically significant results in figures are indicated as follows: ${ }^{*} P<0.05,{ }^{* *} P<0.01,{ }^{* * *} P<0.001$, and ${ }^{* * *} P<0.0001$.

\section{Study approval}

Mice were maintained at the Division of Laboratory Animal Medicine at the UNC Chapel Hill in accordance with protocols approved by the Institutional Animal Care and Use Committee.

\section{Author contributions}

JVG conceived, designed, and coordinated the study. RO, AW, and JVG designed the research experimental studies. RO, AW, and JVG designed the research experimental studies with additional support from PWD, MT, and LØ. RO, AW, MGH, AR, and JVG analyzed the data and wrote the manuscript.

\section{Acknowledgments}

This work was supported in part by NIH grants AI073146, AI1096138, AI111899 (to J.V. Garcia); the UNC Center for AIDS Research grant P30 AI50410 (R. Swanstrom, principal investigator); a Research Fellowship of the Japan Society for the Promotion 
of Science (to T. Nochi); a National Institute of Allergy and Infectious Disease Institutional Training grant (5T32AI007273-27) (to A. Wahl); NIH training grants T32CA9156-37 and F32AI100775 (to M.D. Swanson); and grants received from The Augustinus Foundation, The Danish AIDS Foundation, Danielsen's Foundation, Scandinavian Society for Antimicrobial Chemotherapy, Danish Infectious Diseases Society AP Moeller's Foundation, and Danish Association of Medical Women (to R. Olesen). The funders had no role in study design, data collection and analysis, decision to publish, or preparation of the manuscript. We thank I. Chen for providing pYK-JR-CSF (catalog 2708), J. Kappes for providing pRHPA.c/2635 (catalog 11744), and A.A. Ansari for providing $\alpha 4 \beta 7$ monoclonal antibody (catalog 11718) via the AIDS Research and Reference Reagent Program, Division of AIDS, NIAID.

We also thank Dr. Nana Nikolaishvili-Feinberg and Bentley Midkiff of The Translational Pathology Laboratory at UNC for scanning the IHC images, and we thank former and current members of the Garcia laboratory and husbandry technicians at the UNC Division of Laboratory Animal Medicine for their assistance with aspects of this work.

Address correspondence to: J. Victor Garcia or Angela Wahl, Division of Infectious Diseases, Center for AIDS Research, University of North Carolina School of Medicine, 120 Mason Farm Rd., CB 7042, Genetic Medicine Building 2044, Chapel Hill,
North Carolina 27599-7042, USA. Phone: 919.843.9600; E-mail: victor_garcia@med.unc.edu (J.V. Garcia). Phone: 919.843.9555; E-mail: awahl@med.unc.edu (A.Wahl).

Michael D. Swanson's present address is: Merck Research Laboratories, West Point, Pennsylvania, USA.

Tomonori Nochi's present address is: Laboratory of Functional Morphology, Division of Life Sciences, Department of Animal Biology, Graduate School of Agriculture, Tohoku University, Sendai, Japan.

Morgan Chateau's present address is: Department of Microbiology and Immunology, Keck School of Medicine, University of Southern California, Los Angeles, California, USA.

Julie M. Long's present address is: Department of Clinical Sciences, College of Veterinary Medicine, North Carolina State University, Raleigh, North Carolina, USA.

Paul Denton's present address is: Department of Infectious Diseases, Institute of Clinical Medicine, Aarhus Institute for Advanced Studies, Aarhus University, Aarhus, Denmark.

Amy Richardson's present address is: Google, Mountain View, California, USA.
1. Padian NS, McCoy SI, Balkus JE, Wasserheit JN. Weighing the gold in the gold standard: challenges in HIV prevention research. AIDS. 2010;24(5):621-635.

2. Abdool Karim Q, et al. Effectiveness and safety of tenofovir gel, an antiretroviral microbicide, for the prevention of HIV infection in women. Science. 2010;329(5996):1168-1174.

3. Grant RM, et al. Preexposure chemoprophylaxis for HIV prevention in men who have sex with men. N Engl J Med. 2010;363(27):2587-2599.

4. Curran K, Baeten JM, Coates TJ, Kurth A, Mugo NR, Celum C. HIV-1 prevention for HIV-1 serodiscordant couples. Curr HIV/AIDS Rep. 2012;9(2):160-170.

5. van der Straten A, Van Damme L, Haberer JE, Bangsberg DR. Unraveling the divergent results of pre-exposure prophylaxis trials for HIV prevention. AIDS. 2012;26(7):F13-F19.

6. Thigpen MC, et al. Antiretroviral preexposure prophylaxis for heterosexual HIV transmission in Botswana. N Engl J Med. 2012;367(5):423-434.

7. Van Damme L, et al. Preexposure prophylaxis for $\mathrm{HIV}$ infection among African women. $\mathrm{N} \mathrm{Engl} \mathrm{J}$ Med. 2012;367(5):411-422.

8. Marrazzo JM, et al. Tenofovir-based preexposure prophylaxis for HIV infection among African women. N Engl J Med. 2015;372(6):509-518.

9. Choopanya K, et al. Antiretroviral prophylaxis for HIV infection in injecting drug users in Bangkok, Thailand (the Bangkok Tenofovir Study): a randomised, double-blind, placebo-controlled phase 3 trial. Lancet. 2013;381(9883):2083-2090.

10. Baeten JM, et al. Antiretroviral prophylaxis for HIV prevention in heterosexual men and women.
N Engl J Med. 2012;367(5):399-410.

11. Kashuba AD, Patterson KB, Dumond JB, Cohen MS. Pre-exposure prophylaxis for HIV prevention: how to predict success. Lancet. 2011;379(9835):2409-2411.

12. Cohen MS, et al. Prevention of HIV-1 infection with early antiretroviral therapy. $N$ Engl JMed. 2011;365(6):493-505.

13. Quinn TC, et al. Viral load and heterosexual transmission of human immunodeficiency virus type 1. N Engl J Med. 2000;342(13):921-929.

14. Baeten JM, et al. Genital HIV-1 RNA predicts risk of heterosexual HIV-1 transmission. Sci Transl Med. 2011;3(77):77ra29.

15. Graham SM, et al. Initiation of antiretroviral therapy leads to a rapid decline in cervical and vaginal HIV-1 shedding. AIDS. 2007;21(4):501-507.

16. Nagot $\mathrm{N}$, et al. Longitudinal effect following initiation of highly active antiretroviral therapy on plasma and cervico-vaginal HIV-1 RNA among women in Burkina Faso. Sex Transm Infect. 2008;84(3):167-170.

17. Sheth PM, et al. Persistent HIV RNA shedding in semen despite effective antiretroviral therapy. AIDS. 2009;23(15):2050-2054.

18. Ronen K, Sharma A, Overbaugh J. HIV transmission biology: translation for HIV prevention. AIDS. 2015;29(17):2219-2227.

19. Melkus MW, et al. Humanized mice mount specific adaptive and innate immune responses to EBV and TSST-1. Nat Med.2006; 12(11):1316-1322.

20. Sun Z, et al. Intrarectal transmission, systemic infection, and $\mathrm{CD}^{+} \mathrm{T}$ cell depletion in humanized mice infected with HIV-1. J Exp Med.
2007;204(4):705-714.

21. Denton PW, et al. Antiretroviral pre-exposure prophylaxis prevents vaginal transmission of HIV-1 in humanized BLT mice. PLoS Med. 2008;5(1):e16.

22. Denton PW, et al. Systemic administration of antiretrovirals prior to exposure prevents rectal and intravenous HIV-1 transmission in humanized BLT mice. PLoS One. 2010;5(1):e8829.

23. Denton PW, et al. One percent tenofovir applied topically to humanized BLT mice and used according to the CAPRISA 004 experimental design demonstrates partial protection from vaginal HIV infection, validating the BLT model for evaluation of new microbicide candidates. J Virol. 2011;85(15):7582-7593.

24. Pudney J, Quayle AJ, Anderson DJ. Immunological microenvironments in the human vagina and cervix: mediators of cellular immunity are concentrated in the cervical transformation zone. Biol Reprod. 2005;73(6):1253-1263.

25. Johansson EL, Rudin A, Wassen L, Holmgren J. Distribution of lymphocytes and adhesion molecules in human cervix and vagina. Immunology. 1999;96(2):272-277.

26. Kamat BR, Isaacson PG. The immunocytochemical distribution of leukocytic subpopulations in human endometrium. Am J Pathol. 1987;127(1):66-73.

27. Schulke L, Manconi F, Markham R, Fraser IS. Endometrial dendritic cell populations during the normal menstrual cycle. Hum Reprod. 2008;23(7):1574-1580.

28. Iijima N, Thompson JM, Iwasaki A. Dendritic cells and macrophages in the genitourinary tract. 
Mucosal Immunol. 2008;1(6):451-459.

29. Haase AT. Targeting early infection to prevent HIV-1 mucosal transmission. Nature. 2010;464(7286):217-223.

30. Parrish NF, et al. Phenotypic properties of transmitted founder HIV-1. Proc Natl Acad Sci U S A. 2013;110(17):6626-6633.

31. Jaspan $\mathrm{HB}$, et al. Immune activation in the female genital tract during HIV infection predicts mucosal CD4 depletion and HIV shedding. J Infect Dis. 2011;204(10):1550-1556.

32. McKinnon LR, et al. Characterization of a human cervical $\mathrm{CD} 4^{+} \mathrm{T}$ cell subset coexpressing multiple markers of HIV susceptibility. JImmunol. 2011;187(11):6032-6042.

33. Nkwanyana NN, et al. Impact of human immunodeficiency virus 1 infection and inflammation on the composition and yield of cervical mononuclear cells in the female genital tract. Immunology. 2009;128(1 suppl):e746-e757.

34. Saba E, et al. HIV-1 sexual transmission: early events of HIV-1 infection of human cervico-vaginal tissue in an optimized ex vivo model. Mucosal Immunol. 2010;3(3):280-290.

35. Nawaz F, et al. The genotype of early-transmitting HIV gp120s promotes $\alpha(4) \beta(7)$-reactivity, revealing $\alpha(4) \beta(7)^{+} / \mathrm{CD}^{+} \mathrm{T}$ cells as key targets in mucosal transmission. PLoS Pathog. 2011;7(2):e1001301.

36. Cicala $C$, et al. The integrin $\alpha 4 \beta 7$ forms a complex with cell-surface $\mathrm{CD} 4$ and defines a T-cell subset that is highly susceptible to infection by HIV-1. Proc Natl Acad Sci U S A. 2009;106(49):20877-20882.

37. Quayle AJ, et al. T-lymphocyte profile and total and virus-specific immunoglobulin concentrations in the cervix of HIV-1-infected women. J Acquir Immune Defic Syndr. 2007;44(3):292-298.

38. Koyanagi Y, Miles S, Mitsuyasu RT, Merrill JE, Vinters HV, Chen IS. Dual infection of the central nervous system by AIDS viruses with distinct cellular tropisms. Science. 1987;236(4803):819-822.

39. Morrison CS, et al. Plasma and cervical viral loads among Ugandan and Zimbabwean women during acute and early HIV-1 infection. AIDS. 2010;24(4):573-582.

40. Iversen AK, et al. Distinct determinants of human immunodeficiency virus type 1 RNA and DNA loads in vaginal and cervical secretions. J Infect Dis. 1998;177(5):1214-1220.

41. Cu-Uvin S, et al. Effect of highly active antiretroviral therapy on cervicovaginal HIV-1 RNA. AIDS. 2000;14(4):415-421.

42. Hawes SE, Sow PS, Stern JE, Critchlow CW, Gottlieb GS, Kiviat NB. Lower levels of HIV-2 than HIV-1 in the female genital tract: correlates and longitudinal assessment of viral shedding. AIDS. 2008;22(18):2517-2525.

43. Brenchley JM, et al. $\mathrm{CD} 4^{+} \mathrm{T}$ cell depletion during all stages of HIV disease occurs predominantly in the gastrointestinal tract. J Exp Med. 2004;200(6):749-759

44. Gumbi PP, et al. CD4 T cell depletion at the cervix during HIV infection is associated with accumulation of terminally differentiated $\mathrm{T}$ cells. JVirol. 2011;85(24):13333-13341.

45. Wahl A, et al. Human breast milk and antiretrovirals dramatically reduce oral HIV-1 transmission in BLT humanized mice. PLoS Pathog. 2012;8(6):e1002732.

46. Wahl A, et al. Breast milk of HIV-positive mothers has potent and species-specific in vivo HIV inhibitory activity. J Virol. 2015;89(21):10868-10878.

47. Chateau M, Swanson MD, Garcia JV. Inefficient vaginal transmission of tenofovir-resistant HIV-1. JVirol. 2013;87(2):1274-1277.

48. Kovarova M, et al. Nanoformulations of rilpivirine for topical pericoital and systemic coitus-independent administration efficiently prevent HIV transmission. PLoS Pathog. 2015;11(8):e1005075.

49. Stevceva L, et al. Cervicovaginal lamina propria lymphocytes: phenotypic characterization and their importance in cytotoxic T-lymphocyte responses to simian immunodeficiency virus SIVmac251. JVirol. 2002;76(1):9-18

50. Veazey RS, Marx PA, Lackner AA. Vaginal CD4 ${ }^{+}$ $T$ cells express high levels of CCR5 and are rapidly depleted in simian immunodeficiency virus infection. J Infect Dis. 2003;187(5):769-776.

51. Lennox JL, et al. Safety and efficacy of raltegravir-based versus efavirenz-based combination therapy in treatment-naive patients with HIV-1 infection: a multicentre, double-blind randomised controlled trial. Lancet. 2009;374(9692):796-806.

52. Rockstroh JK, et al. Long-term treatment with raltegravir or efavirenz combined with tenofovir/emtricitabine for treatment-naive human immunodeficiency virus-1-infected patients: 156-week results from STARTMRK. Clin Infect Dis. 2011;53(8):807-816.

53. Denton PW, et al. Generation of HIV latency in humanized BLT mice. JVirol. 2012;86(1):630-634.

54. Strategies for Management of Antiretroviral Therapy Study G, et al. CD4 ${ }^{+}$count-guided interruption of antiretroviral treatment. $\mathrm{N} \mathrm{Engl} \mathrm{J} \mathrm{Med.}$ 2006;355(22):2283-2296.

55. Lori F, Lisziewicz J. Structured treatment interruptions for the management of HIV infection. JAMA. 2001;286(23):2981-2987.

56. Denton PW, et al. Targeted cytotoxic therapy kills persisting HIV infected cells during ART. PLoS Pathog. 2014;10(1):e1003872.

57. Mkhize NN, et al. Persistence of genital tract $\mathrm{T}$ cell responses in HIV-infected women on highly active antiretroviral therapy. J Virol. 2010;84(20):10765-10772.

58 . Valea $\mathrm{D}$, et al. $\mathrm{CD}^{+}{ }^{+} \mathrm{T}$ cells spontaneously producing human immunodeficiency virus type I in breast milk from women with or without antiretroviral drugs. Retrovirology. 2011;8:34.

59. UNAIDS. 2009 AIDS Epidemic Update. Geneva, Switzerland:WHO; 2009.

60. Miller CJ, Alexander NJ, Vogel P, Anderson J, Marx PA. Mechanism of genital transmission of SIV: a hypothesis based on transmission studies and the location of SIV in the genital tract of chronically infected female rhesus macaques. J Med Primatol. 1992;21(2-3):64-68.

61. Li Q, et al. Glycerol monolaurate prevents mucosal SIV transmission. Nature. 2009;458(7241):1034-1038.

62. Howell AL, et al. Human immunodeficiency virus type 1 infection of cells and tissues from the upper and lower human female reproductive tract. J Virol. 1997;71(5):3498-3506.

63. Cameron PU, Freudenthal PS, Barker JM,
Gezelter S, Inaba K, Steinman RM. Dendritic cells exposed to human immunodeficiency virus type- 1 transmit a vigorous cytopathic infection to $\mathrm{CD} 4^{+} \mathrm{T}$ cells. Science. 1992;257(5068):383-387.

64. Wu L, KewalRamani VN. Dendritic-cell interactions with HIV: infection and viral dissemination. Nat Rev Immunol. 2006;6(11):859-868.

65. Arrighi JF, et al. DC-SIGN-mediated infectious synapse formation enhances X4 HIV-1 transmission from dendritic cells to T cells. J Exp Med. 2004;200(10):1279-1288.

66. McDonald D, Wu L, Bohks SM, KewalRamani VN, Unutmaz D, Hope TJ. Recruitment of HIV and its receptors to dendritic cell-T cell junctions. Science. 2003;300(5623):1295-1297.

67. Geijtenbeek TB, et al. DC-SIGN, a dendritic cell-specific HIV-1-binding protein that enhances trans-infection of T cells. Cell. 2000;100(5):587-597.

68. Hladik F, et al. Initial events in establishing vaginal entry and infection by human immunodeficiency virus type-1. Immunity. 2007;26(2):257-270.

69. Miller CJ, Hu J. T cell-tropic simian immunodeficiency virus (SIV) and simian-human immunodeficiency viruses are readily transmitted by vaginal inoculation of rhesus macaques, and Langerhans' cells of the female genital tract are infected with SIV. J Infect Dis. 1999;179(suppl 3):S413-S417.

70. Gupta P, et al. Memory CD4(+) T cells are the earliest detectable human immunodeficiency virus type 1 (HIV-1)-infected cells in the female genital mucosal tissue during HIV-1 transmission in an organ culture system. JVirol. 2002;76(19):9868-9876.

71. Zhang Z, et al. Sexual transmission and propagation of SIV and HIV in resting and activated CD $4^{+}$ T cells. Science. 1999;286(5443):1353-1357.

72. Miller CJ, et al. Propagation and dissemination of infection after vaginal transmission of simian immunodeficiency virus. J Virol. 2005;79(14):9217-9227.

73. Maher D, Wu X, Schacker T, Horbul J, Southern P. HIV binding, penetration, and primary infection in human cervicovaginal tissue. Proc Natl Acad Sci U S A. 2005;102(32):11504-11509.

74. Wheeler LA, et al. Inhibition of HIV transmission in human cervicovaginal explants and humanized mice using CD4 aptamer-siRNA chimeras. JClin Invest. 2011;121(6):2401-2412.

75. Abel K, Rocke DM, Chohan B, Fritts L, Miller CJ Temporal and anatomic relationship between virus replication and cytokine gene expression after vaginal simian immunodeficiency virus infection. J Virol. 2005;79(19):12164-12172.

76. Reynolds MR, et al. CD8 ${ }^{+} \mathrm{T}$-lymphocyte response to major immunodominant epitopes after vaginal exposure to simian immunodeficiency virus: too late and too little. J Virol. 2005;79(14):9228-9235.

77. Ferenbach D, Hughes J. Macrophages and dendritic cells: what is the difference? Kidney Int . 2008;74(1):5-7.

78. Strobl H, et al. Identification of CD68+linperipheral blood cells with dendritic precursor characteristics. JImmunol. 1998;161(2):740-748. 
79. Segerer S, et al. Compartment specific expression of dendritic cell markers in human glomerulonephritis. Kidney Int. 2008;74(1):37-46.

80. de Saint-Vis B, et al. The cytokine profile expressed by human dendritic cells is dependent on cell subtype and mode of activation. J Immunol. 1998;160(4):1666-1676.

81. Woltman AM, et al. Quantification of dendritic cell subsets in human renal tissue under normal and pathological conditions. Kidney Int. 2007;71(10):1001-1008.

82. Lazarovits AI, et al. Lymphocyte activation antigens. J Immunol. 1984;133(4):1857-1862.

83. Palmer S, et al. New real-time reverse transcriptase-initiated PCR assay with single-copy sensitivity for human immunodeficiency virus type 1 RNA in plasma. J Clin Microbiol. 2003;41(10):4531-4536.

84. Rubenstein LM, Davis CS. Estimation of the average correlation coefficient for stratified bivariate data. Stat Med.1999;18(5):567-580.

85. Efron B, Tibshirani R. An Introduction To The Bootstrap. 1st ed. London, United Kingdom: Chapman and Hall/CRC; 1993. 